\title{
GÊNERO E COLONIALISMO. A VIOLÊNCIA CONTRA A MULHER E A COLONIZAÇÃO EM OUR LADY OF THE MASSACRE (1979), DE ANGELA CARTER
}

\author{
Daniela de Cássia Berlotti Traspadini Oliveira
}

Silvio Ruiz Paradiso

\begin{abstract}
RESUMO: A intersecção entre pós-colonialismo e feminismo tem como foco negligenciadas questões: o colonizado e a mulher, respectivamente. Enquanto o feminismo - abordando as questões de gênero e sexualidade - tenta lutar para a libertação da mulher sob o sistema patriarcal, o póscolonialismo oferece ao colonizado a oportunidade de lutar contra o legado imperialista. Há uma acentuada preocupação, tanto do pós-colonialismo como do feminismo, sobre a importância da linguagem para a formação da identidade e para a construção da subjetividade. O presente artigo propõe uma análise do conto Our Lady of the Massacre (1976), de Angela Carter. A partir da teoria pós-colonial, analisar-se-á o colonialismo, o gênero e a violência sofrida pela mulher diante do patriarcalismo, além de uma relação análoga mulher/colônia.
\end{abstract}

PALAVRAS-CHAVE: Pós-colonialismo. Gênero. Patriarcalismo. Feminismo. Angela Carter.

ABSTRACT: The intersection between postcolonialism and feminism focuses on neglected issues: the colonized and women, respectively. While feminism - addressing issues of gender and sexuality - tries to struggle for the liberation of women under the patriarchal system, the Post-colonialism offers to the colonized the opportunity to fight against the imperialist legacy. There is a marked preoccupation of both post-colonialism and feminism about the importance of language in identity formation and construction of subjectivity. This paper proposes an analysis of short story Our Lady of the Massacre (1976), by Angela Carter. From the post-colonial theory, it will examine colonialism, gender and violence suffered by women from the patriarchy, in an analog relation woman / colony.

KEYWORDS: Postcolonialism. Gender. Patriarcalism. Feminism. Angela Carter.

\section{CONSIDERAÇÕES INICIAIS}

Segundo Bonnici (2009, p. 262),

o termo colonialismo caracteriza o modo peculiar como aconteceu a exploração cultural durante os 500 anos causada pela expansão européia." O colonizador, representante da civilização europeia, fundamentada na ideologia da supremacia da raça branca, cristã e patriarcal desempenhava o papel de "impor a civilização européia ao resto do mundo.

Através do discurso colonialista hegemônico, procurava desenvolver a "tarefa civilizadora", que consistia em subjugar os colonos em benefício, a qualquer custo, da 
metrópole. O relacionamento entre colonizador e colonizado era baseado no sistema de diferença hierárquica, desigual e injusto.

Abrangendo cultura e literatura, a crítica pós-colonial ocupa-se em sondá-las durante o domínio do Império Europeu, a fim de revelar suas consequências sobre as literaturas contemporâneas. A partir da teoria pós-colonial, podemos enxergar os resultados desastrosos da colonização e observar nova estética literária, a do ponto de vista do excluído. Podemos afirmar, então, que há grande afinidade entre os estudos pós-coloniais e o feminismo. Se compararmos patriarcalismo/feminismo com metrópole/colônia, observaremos que a mulher sofre com o patriarcalismo da mesma maneira que o colono sofre nas mãos do colonizador, que representa a metrópole. Sendo assim, se o homem foi colonizado, nas sociedades póscoloniais, a mulher é duplamente colonizada (BONNICI, 2007, p. 67). A dupla colonização, de acordo com Bonnici (2007, p. 67), "é a subjugação da mulher nas colônias, objeto do poder imperial em geral e da opressão patriarcal colonial e doméstica.”

Sob essa perspectiva, o conto analisado será Our Lady of the Massacre (1979), da escritora inglesa Angela Carter, reconhecida por sua literatura pós-feminista. Em Our Lady of the Massacre, Carter associa história e ficção, contrariando os padrões hegemônicos europeus e abordando assuntos controversos para aquela época (período histórico de avanço colonial inglês em terras norte--americanas), como, por exemplo, colonização, gênero, miscigenação, violência contra mulher e feminismo (PARADISO; BARZOTTO, p. 107, 2010). A protagonista (Sal) - uma mulher branca europeia - sofre violência sexual, fato que a leva à prostituição e, por esse motivo, é banida à colônia inglesa, na América, onde continua sendo alvo de perseguição sexual ao cumprir sua pena em trabalhos forçados, na agricultura. Num esforço para sobreviver diante da marginalização que lhe fora imposta, Sal foge para uma tribo indígena, onde é aceita e passa a fazer parte dela.

Na tribo dos índios algoquianos, a narradora conhece uma vida totalmente diferente da que conhecera em sua cultura original, pois, desde muito cedo, fora perseguida sexualmente e violentada: entre os da sua origem a jovem sempre fora vítima da violência a que estavam sujeitas as mulheres da época. (AUAD, apud BONNICI, 2007, p. 262) comenta:

A violência contra as mulheres é qualquer ato de violência baseado no gênero cujo resultado seja causar dano ou sofrimento físico, sexual ou 
psicológico às mulheres, incluindo ameaças, coerção, privação arbitrária de liberdade, na vida pública ou na vida privada.

Dessa maneira, através do estudo do conto de Carter e de pesquisas bibliográficas de teóricos com autoridade reconhecida sobre o assunto, pretende-se revelar, elucidar, esclarecer os efeitos catastróficos, tanto os da colonização como os da violência contra a mulher, bem como suas consequências para a vida de ambos. A fim de compreender melhor os conceitos expostos, primeiramente abordaremos a biografia de Angela Carter e a fábula do conto em questão.

\section{ANGELA CARTER \& OUR LADY OF THE MASSACRE (1979)}

Carter nasceu em Sussex, Reino Unido, em 7 de maio de 1940. Na Segunda Guerra Mundial, para fugir de bombardeios em sua cidade natal, foi levada a Yorkshire, para viver com sua avó materna, uma mulher de personalidade forte e matriarcal que, com certeza, a influenciou como pessoa e escritora. Em 1960, após ter recebido seu diploma de licenciatura em Inglês, com especialização em literatura medieval, Carter casou-se com Paul Carter. Seu primeiro romance foi "Shadow Dance", publicado em 1966. O último trabalho foi "Wise Children”, publicado em 1991, ano em que recebeu um diagnóstico de câncer no pulmão, vindo a falecer no ano seguinte, 1992 (STODDART, 2007, p. 3).

Seu trabalho representa uma combinação bem sucedida de teorias literárias pósmodernas e políticas feministas. Sua obra compreende vários romances, uma coleção de contos, dois livros de não ficção e uma tradução de contos franceses e europeus para o inglês. A violência, o sexo e o feminismo compõem os principais temas de ficção de suas obras; a grande maioria de seus personagens é libertina, alguns hediondos. A peculiaridade admirável está em seu vasto vocabulário e seu estilo riquíssimo, inconfundível.

Carter, diferentemente de outros escritores da época, fortalece o raciocínio do absolutismo masculino patriarcal. Para Kendrik (apud BONNICI, 2000, p. 165), "Carter aprecia o absurdo do aparato masculino, o ridículo do instrumento dominador do mundo que uma simples tesoura pode extirpar." 
Os escritos de Carter fazem parte do cânone literário inglês, e sua reputação como escritora na Inglaterra é elevada. Apesar de todos os seus livros terem sido publicados nos Estados Unidos, seu nome está ligado a nomes de escritores nada convencionais, que amedrontam o leitor comum. Embora alguns livros da escritora tenham sido publicados no Brasil, não alcançaram grande público (BONNICI, 2000).

O conto Our Lady of The Massacre, publicado em The Saturday Night Reader, 1979, mais tarde foi incorporado à coleção de contos The Black Venus. A ousadia da escritora é detectada ao tecer um conto que combina ficção e história, registrando, em sua escrita, temas controversos para aquele momento histórico, como miscigenação, colonização, gênero, religiosidade, etc. Esses temas poderiam colocar em xeque os padrões hegemônicos europeus da época (PARADISO; BARZOTTO, p. 108, 2010).

A relevância do conto está em a narradora/protagonista ser uma mulher inserida no ambiente colonial e que escreve sua história do ponto de vista feminista e pós-colonial, e no fato de toda a narrativa ser permeada pelo feminismo que permite à narradora rejeitar sua condição de objetificação, afirmando-se como sujeito ao assumir o comando do seu próprio destino.

"Our Lady of The Massacre” narra a história de uma jovem mulher branca européia, que se torna órfã de pai e mãe ainda na infância. Ela é levada para trabalhar na casa de uma senhora que professava a fé romana e fazia previsões sobre o futuro, e que nunca havia se casado, como a própria narradora relata: "This old woman [...] never married..." ${ }^{1}$ (CARTER, 2004, p. 274). Após a morte dessa senhora, a jovem decide ir para Londres, onde ela acreditava que poderia fazer fortuna. Chegando lá, começa a roubar para satisfazer a fome, até conhecer um cavalheiro que a ludibria e usurpa sua virgindade. Em seguida, ela inicia uma vida de prostituição.

A protagonista admite não se contentar apenas com a prostituição; aproveita da luxúria de seus clientes para saquear seus bens clandestinamente, até ser condenada à prisão pelo roubo de um relógio de ouro de um vereador, na prisão, também recebe uma marca em sua mão, que a identificará como criminosa pelo resto dos seus dias. Por esse motivo, é banida à colônia inglesa na América, do outro lado do Atlântico, sendo obrigada a trabalhar numa plantação de fumo da Virgínia.

1 Esta velha mulher [...] nunca se casou. (tradução nossa). 
Enquanto cumpre sua pena, continua sendo alvo de perseguição sexual. O dono da plantação se afeiçoa a ela e a coloca para trabalhar em serviços domésticos na sua casa. No entanto, o capataz responsável pela plantação a importuna, dizendo que uma prostituta de Cheapside como ela não deveria brincar de ser uma empregada doméstica honesta na Virgínia. Ele, sabendo do seu passado de meretrício, a assedia intensamente, acreditando que por seus antecedentes na prostituição e por sua condição duplamente objetificada, como mulher e como prisioneira, ela deve ceder aos seus caprichos masculinos. O assédio se torna uma tentativa de estupro e a jovem é atacada sexualmente pelo supervisor, que, autoritário, lhe diz que irá possuí-la, quer ela queira ou não. Em resposta à tentativa de estupro, ela comete um ato deliberado: decepa fora as orelhas do homem e foge, sem destino.

$\mathrm{Na}$ fuga, encontra um jardineiro (escravo), que a chama de Sal e lhe dá algum suprimento, aconselhando-a a fugir para o deserto. E ela prossegue em sua fuga até chegar à tribo indígena dos algoquianos, onde tem seu primeiro encontro com uma parteira nativa, que resolve adotá-la como filha, ensinando-lhe tudo o que ela necessita, para viver naquela comunidade.

$\mathrm{Na}$ tribo, a protagonista aprende o idioma algoquiano, vivencia novos costumes e assimila valores que a levarão a assumir uma personalidade indígena, em busca de uma vida mais justa e sem o sofrimento, que conhecera em sua sociedade de origem. Casa-se com um guerreiro da tribo, chamado Tall Hickory, e eles têm um filho, a quem dão o nome de Little Shooting Star.

Nesse tempo há um aparente período de paz entre índios e europeus, que é interrompido com a captura e morte do governador da Virgínia pelos índios. O que se segue é uma vingança dos soldados ingleses que, aproveitando um momento de embriaguez dos índios, massacram sem piedade toda aquela tribo. Somente algumas mulheres são poupadas, entre elas a narradora e seu filho, que tem sua vida ameaçada ao ser descoberta como desertora inglesa.

O capitão do massacre intenta entregar a jovem ao poder público para que seja enforcada e ele receba a recompensa por sua cabeça, porém, chegando a um vilarejo, um ministro puritano e sua esposa se afeiçoam a ela e ao seu filho e oferecem dinheiro para que ela e a criança fiquem morando com o casal, que não pode ter filhos. Sal, como é chamada pelo jardineiro que a vê fugir, permanece na casa do pastor e sua esposa, que sempre 
aconselha a moça a se casar com um inglês e deixar seu filho com ela, propostas que são recusadas com veemência pela protagonista.

\section{GÊNERO E COLONIALISMO}

O termo gênero é utilizado originalmente na gramática para explicar o emprego de desinências distintas que tendem estabelecer a diferença de sexo para seres ou coisas sexuadas. No entanto, a crítica feminista absorveu o termo gênero para estabelecer uma relação entre as características culturais respectivas a cada um dos sexos e à sua constituição biológica. Assinalando a formação social das diferenças sexuais, gênero aponta para cultura no que se refere às categorizações entre masculino e feminino. Assim sendo, a constituição de gênero, em virtude do sexo, compõe o sujeito a partir das peculiaridades linguísticas e dos aspectos culturais constituídos de acordo com as categorias sociais em que está inserido (ZOLIN, 2009).

A representação do homem como centralizador do poder e dono de uma posição elevada na sociedade são indicadores de uma cultura machista e patriarcal. Essa ideologia confere à mulher a marginalidade, a exclusão, a opressão, continuamente afirmada por um discurso autoritário que privilegia o homem, através de clichês e de atos preconcebidos que impõem limites às mulheres, conferindo-lhes um lugar inferior na sociedade. A exemplo disto, cita-se o discurso colonialista, pura e exclusivamente encabeçado por homens. Entendese que, no universo binário dos impérios, tanto o outro/colonizado quanto a mulher permanecem no mesmo polo, significativamente antagônico ao polo do Outro/colonizador, homem.

Confirmando esse pressuposto, o discurso imperial europeu, abarrotado de superioridade, ambiciona o controle social e ideológico dos povos colonizados, atribuindolhes uma condição subalterna. "Gerações de europeus se convenciam de sua superioridade cultural e intelectual diante da 'nudez' dos ameríndios [...], tomavam como fato indiscutível a inferioridade da mulher" (BONNICI, 2009, p. 257).

A equivalência entre imperialismo e patriarcalismo nos permite inferir que ambos exercem poderes equivalentes de subjugação, simultaneamente, sobre o colonizado e a 
mulher. "Há muita semelhança entre a experiência da mulher no patriarcalismo e a experiência do sujeito colonizado, contra os quais o feminismo e o pós-colonialismo reagem" (BONNICI, 2007, p. 209).

A mulher está fadada a suportar a opressão imposta pelo sistema patriarcal, que insiste em conferir a ela um papel inferior ao do homem, semelhantemente, o colono também padece diante da posição de superioridade assumida pelo colonizador, que exerce poder sobre o indivíduo colonizado através do seu discurso, impondo ao nativo a marginalização.

O feminismo - entendido como movimento legítimo, preconizador na implantação dos direitos políticos e sociais da mulher - é, portanto, de interesse vital para o discurso póscolonial. Isso porque ambos, feminismo e pós-colonialismo, atribuem à linguagem fundamental importância para a formação da identidade e construção da subjetividade do indivíduo (ASHCROFT, 1998, p. 102).

Em Our Lady of The Massacre, logo no início da narrativa, a autora concede voz à sua protagonista de maneira muito peculiar e contraditória para os escritos da época: "My name is neither here nor there since I used several in the Old World that I may not speak of now; then there is my, as it were, wilderness name, that now I never speak of; and, now, what I call myself in this place" 2 (CARTER, 2004, p. 274).

Assevera Moi (1990, apud BONNICI, 2000, p. 172): "Dar nome é exercer poder.” A jovem de Lancaster não revela seu verdadeiro nome; ela deseja mantê-lo no anonimato. Apesar de ser chamada de Sal por um personagem (Sal uma corruptela do termo hispânico salerosa, que significa 'graciosa') e de Maria pela esposa do ministro puritano (uma tentativa de analogia com a subalternidade da casta e servidora mãe de Cristo), ela mesma não assume nenhum deles, faz questão de dizer que tem vários; entretanto, eles não serão mencionados por ela.

Conforme Bonnici (2000, p. 168), “o fato de ser sem nome e o fato de ter uma pluralidade de nomes a fazem o sujeito de sua identidade, usando todos ou nenhum para

\footnotetext{
${ }^{2}$ Meu nome não é nem daqui nem de lá, desde quando usei vários no Velho Mundo, nomes dos quais eu não posso falar agora; então meu nome, da mesma forma como era, um nome selvagem, nunca o falo, mas que chamo a mim mesmo neste lugar [de selvagem] (tradução nossa). Aqui, Sal relata que o nome pouco importa, pois fora tratada como selvagem no Velho Mundo (Europa), e que agora, na América, esquece o nome europeu de batismo e assume o nome de selvagem.
} 
escapar das restrições do logocentrismo ${ }^{3}$." O nome é uma marca de identidade, logo, ela evita professar alguma, pois ainda não a encontrou. Apesar de ser inglesa, não se considera mais como tal, devido a tudo que passou. Isso pode ser considerado como indício de uma futura transculturação. Por esse motivo, antes mesmo que a narradora comece a contar sua história, ela faz questão de deixar bem claro o seu poder sobre sua existência, construída por ela mesma, por meio de muito sofrimento ao longo dos anos. E ela o faz, por meio do seu discurso, afirmando sua gerência sobre seu nome, ou a ausência dele, e, consequentemente, sobre sua identidade.

Perder os pais muito cedo; ir trabalhar como empregada, quando ainda era uma criança; ser enganada por um inglês a ponto de perder sua inocência; conseguir seu próprio sustento através da prostituição e de roubos; ser presa; ter seu corpo marcado; ser exilada e obrigada a trabalhos forçados; sofrer perseguição sexual, defender-se dela (da perseguição); ter que reagir à tentativa de estupro, cortando as orelhas de seu algoz; fugir sem destino para não ser morta; ser capaz de prover seu próprio alimento na floresta durante sua fuga; penetrar em uma cultura totalmente diferente da sua de origem, adaptar-se a ela, absorvendo seus costumes, casar-se com um índio algoquiano e ter um filho com ele; testemunhar o martírio de seu marido e de um povo adotado por ela como seu; ser quase violentada novamente por um soldado inglês; ser capturada por uma tropa que a entregaria às autoridades como desertora, para ser enforcada; readaptar-se à sua cultura de origem para garantir sua sobrevivência e a do filho, afirmar-se como dona da sua vontade ao negar os conselhos da esposa do pastor - tudo isso marcou os passos do seu viver.

Todas essas experiências lhe deram força e coragem de assumir-se como sujeito, como mulher independente, inteiramente capacitada pelas situações conflituosas experimentadas e superadas por ela. Cada limitação, suplantada através de seu próprio esforço, fez com que ela se tornasse "autônoma" e com todo o direito, pelo menos aos seus próprios olhos, de exercer autoridade sobre sua própria vida, tornando-se livre para nomear-se a si mesma da maneira que achasse mais conveniente.

\section{UMA QUESTÃO DE GÊNERO: MULHER/SUJEITO X HOMEM/OBJETO}

3 Termo cunhado pelo filósofo alemão Ludwig Klages nos anos de 1920 e se refere à tendência no pensamento ocidental de se colocar o logos (palavra ou razão no grego) como o centro de qualquer texto ou discurso. 
Conforme explicita Zolin (2009, p. 219)

Categorias utilizadas para caracterizar as tintas do comportamento feminino em face dos parâmetros estabelecidos pela sociedade patriarcal: a mulhersujeito é marcada pela insubordinação aos referidos paradigmas, por seu poder de decisão, dominação e imposição; enquanto a mulher-objeto definese pela submissão, pela resignação e pela falta de voz.

A narrativa é bem marcada pela identificação que existe entre as personagens mulheres, que, de algum modo, resistem à supremacia do regime patriarcal. A velha dama para a qual a narradora vai trabalhar, quando ainda era criança, apresenta, em sua história, marcas do sistema patriarcal, pois temos o relato de que seu pai desejava ter um filho, porém, não tendo, ensinou-a como se ensinaria a um filho homem. Ele lhe ensinou o latim, o grego, um pouco de hebraico e noções sobre astronomia. "Besides, her father, wanting a son and getting now but she, taught her Latin, Greek and a bit of Hebrew and left her a great telescope with which she used to view the heavens [...]"4 (CARTER, 2004, p. 274).

Esse trecho reforça a ideia de subjugação da mulher - difundida pelo patriarcalismo de que ela deve desempenhar apenas afazeres que estejam ligados ao seu papel de esposa, mãe, dona de casa, sendo até mesmo relegada ao analfabetismo, deixando, a cargo do homem, trabalhos mais "ilustres", reconhecidos, elevados, que fortalecem e dão continuidade a conceitos falocêntricos, disseminados na época. Bonnici (2007, p. 194) esclarece:

A opressão feminina é o resultado de uma estruturação de poder pela qual a ideologia masculinista e a Weltanschauung 5 masculina dominam a totalidade da sociedade humana, deixando a mulher hierarquizada e restrita a funções societárias estritamente ligadas à sua biologia.

\footnotetext{
${ }^{4}$ Além disso, seu pai, querendo um filho, mas não recbendo nada a não ser ela[uma menina], lhe ensinou latim, grego e um pouco de hebraico, deixando um grande telescópio com o qual ela costumava ver os céus [...]. (Tradução nossa)

${ }^{5}$ Weltanschauung masculina termo de origem alemã que significa literalmente visão de mundo ou cosmovisão. É a orientação cognitiva de um indivíduo ou grupo, isto é, sua visão ideológica de mundo, neste caso, masculina (patriarcalismo). (Nota dos autores).
} 
Mesmo assim, a solteirona aproveitou os ensinamentos de seu pai para prosperar, fazendo negócios muito bem sucedidos que a deixaram rica. Nunca se casou, era autossuficiente, poderia subsistir por si mesma. Ela ensinou tudo que sabia à sua "querida criança", nome carinhoso dado à narradora pela velha dama, que a considerava como uma pessoa muito próxima.

A aproximação também acontece com a parteira indígena, que mostra receptividade com a protagonista assim que a vê e, posteriormente, a adota como filha, introduzindo-a na cultura da tribo dos algoquianos.

Quando a narradora vê a índia, resolve abrir seu corpete e mostrar-lhe os seios, como que dizendo que também seria capaz de amamentar como a índia, afinal ambas eram mulheres, mesmo que de diferentes etnias “[...] and it came into my mind to open my bodice, show her my breasts, that, though I had whiter skin, I could give suck as well as she and she reached out and touched my bosom" 6 (CARTER, 2004, p. 280).

A índia estende sua mão e toca no seio da protagonista, num ato de identificação, que evidencia uma ligação corporativista entre essas duas mulheres distintas, porém unidas por sua condição subalterna. Essa atitude caracteriza o termo female bonding, que, conforme definição de Bonnici (2007, p. 83, 84), compreende

a solidariedade interfeminina praticada por mulheres para romper ou aniquilar as estratégias patriarcais. [...] Female bonding inscreve (1) grau de confiança que as personagens femininas tem entre si, (2) o apoio que uma dá a outra e (3) o estabelecimento de uma cultura feminina diferente e distinta do mundo masculino e capaz de se exercitar conforme valores e atitudes diferentes.

Logo após esse momento de reconhecimento entre as duas mulheres, a índia vê o espartilho - que pode representar a tirania sufocante do patriarcalismo - da jovem, lamenta

\footnotetext{
${ }^{6}[\ldots]$ e veio em minha mente para que eu abrisse meu corpete, mostrar-lhe os meus seios, que, embora tivesse a pele mais branca, eu poderia dar mamar tão bem quanto ela, e ela estendeu a mão e tocou meu seio. (Tradução nossa).
} 
com um gemido e sugere, apenas com seu olhar, que ela não precisaria mais daquele aparato no lugar em que se encontrava. A jovem entende a mensagem e, após se livrar da peça, declara que pode respirar melhor sem o acessório: "So off go my stays and I throws them into a bush and breathes easier for it" 7 (CARTER, 2004, p. 280). Logo após esse episódio, a narradora é conduzida à tribo, da qual passa a fazer parte.

As duas mulheres que se unem à protagonista têm algo em comum: tanto a velha dama quanto a parteira indígena nunca foram casadas, o que, dentro da narrativa, fortalece a subjetificação da mulher, levando-as a independência e autonomia. As duas, de certo modo, adotam a narradora, oferecendo a ela conhecimentos que a subsidiarão em sua sobrevivência e luta contra a opressão imposta pelo sistema patriarcal.

Essas mulheres criam vínculos relacionais e compartilham experiências boas e ruins que as fazem evoluir em sua subjetificação, aproveitando as lições extraídas de cada situação vivida por elas como elementos ativos na sua luta contra opressão dos regimes colonial e patriarcal.

De acordo com Bonnici (2000, p.168), "uma vida compartilhada faz que as circunstâncias difíceis se tornem mais fáceis para as mulheres no patriarcalismo, além de ter um efeito salvífico para a jovem em particular."

Enquanto as mulheres são apresentadas na narrativa como trabalhadoras, detentoras de diversos conhecimentos, ativas, independentes, os homens, principalmente os europeus, são apresentados como preguiçosos, covardes, aproveitadores, mercenários, numa tentativa de desconstruir a imagem de sujeito do homem.

Há exemplos usados pela autora, bem convincentes, na intenção de objetificação do masculino: o senhor desocupado que ela conheceu em Londres que a seduziu e violentou, o capataz da plantação de fumo na Virgínia, que tenta estuprá-la, a embriaguez dos guerreiros da tribo pouco antes do massacre, os soldados ingleses, que chacinam toda a tribo dos algoquianos e viloletam as índias antes de matá-las e o próprio reverendo inglês que a utiliza como empregada. São vários e bastantes os elementos oferecidos pela narradora para a desconstrução da imagem do homem como sujeito, como superior, conforme ditavam as convenções da época.

\footnotetext{
7 “Então, eu retirei o que estava em mim e lancei-os no arbusto, podendo respirar melhor por isso. (Tradução Nossa)
} 
A forma de reação da jovem diante das atitudes medíocres dos homens que cruzam seu caminho também tem importante significado nessa tarefa de subverter a condição de sujeito do homem. No episódio do capataz, por exemplo, a protagonista faz questão de assegurar sua autoridade sobre o próprio corpo, desafiando seu poder fálico ao cortar-lhe fora as orelhas (BONNICI, 2000), o que para ela ainda parece insuficiente, de acordo com a afirmação que segue: "Well," says I, "the overseer just now tried to board me and I've had the ears off him and would it had been his pillocks too" 8 (CARTER, 2004, p. 277).

Da mesma forma, quando sofre a segunda tentativa de estupro, resiste e afirma novamente sua subjetividade ao dizer que o soldado precisaria da força de dez homens para fazê-lo, recobrando sua feminilidade, restabelecendo o domínio sobre seu desejo, sobre seu corpo.

\section{VIOLÊNCIA CONTRA A COLÔNIA E A MULHER}

A partir da teoria pós-colonial, podemos entender que o europeu declara-se como sujeito, assumindo uma posição de superioridade, garantida pelo seu lugar de preeminência no topo das sociedades pós-coloniais. Essa ideia lhe permite pensar, arrogantemente, que a civilização europeia é o centro do mundo e única detentora de toda ciência e conhecimento existente, considerando como periferia as outras nações e povos colonizados, marginalizandoos como selvagens, ignorantes e culturalmente subdesenvolvidos (BONNICI, 2009).

De acordo com esse entendimento, a narradora registra :"I had heard these Indians were mortal dragons, accustomed to eat the flesh of dead men, but the pretty little naked children playing with their dollies in the dust, oh!" 9 (CARTER, 2004, p. 281). Partindo da imagem que os colonizadores tinham dos povos nativos, a colônia era vista por eles então como uma fonte de riquezas inesgotáveis e a razão maior da sua existência seria contribuir para o benefício da metrópole e para o aumento do seu domínio sobre a terra.

\footnotetext{
8 "Bem", eu disse, o superintendente agora tentara embarcar comigo e eu arranquei-lhe as orelhas, melhor seria ter arrancado seu saco escrotal também. (Tradução Nossa).

${ }^{9}$ Eu tinha ouvido que esses índios eram dragões mortais, acostumados a comer a carne de homens mortos, mas [vi] as pequenas e bonitas crianças nuas brincando com seus carrinhos na poeira, oh! (Tradução Nossa).
} 
Por isso, o europeu não via nenhuma restrição em invadir de maneira violenta e arbitrária, extraindo da terra toda fonte de riqueza existente, usando-a como se fora sua, sem importar-se com sua preservação. Os verdadeiros donos da terra eram tratados de igual forma ou até pior, pois a esses era imposta nova língua, nova religião, novos costumes, reprimindo sua cultura de origem.

A maneira impetuosa como a colônia era violentada poderia caracterizar praticamente um estupro, que pode ser definido como a ação repugnante para coagir a mulher ao ato sexual, empregando ameaça ou violência. Esse ato deliberado e violento do homem está intimamente ligado ao poder fálico masculino, reafirmado pelo sistema patriarcal e machista e também à disparidade de gênero fortalecida por essas ideologias. Em sua concepção, Azevedo (1995, p. 24) corrobora:

O estupro é sempre um ato de violência, cuja força física masculina é o exercício perverso da dominação do macho sobre a fêmea, e esse ato voluntário e maldoso da força física constitui o que se poderia chamar de face brutal da falocracia, ou seja, da hegemonia masculina que visa assegurar que a mulher esteja sempre em posição de inferioridade e não subverta a ordem vigente.

Na dimensão colonial, as mulheres são duplamente colonizadas. Em primeiro lugar, pelo colonizador, condição que se estende a todos os membros da colônia; em segundo lugar, a que ocorre justamente pelo fato de ser mulher, resultante do sistema patriarcal. Desse modo, levando-se em consideração a problemática da raça e da classe, a mulher torna-se duas vezes objetificada (BONNICI, 2000).

A violência contra a mulher pode ser caracterizada de diversas maneiras, desde a agressão verbal até a violência sexual, ao estupro. Dentre as inúmeras formas de violência contra a mulher, BAKER e TONER (apud BONNICI, 2007, p. 260; 261) explicitam:

Parece que o estupro, o mais hediondo dos crimes sexuais, tenha derivado historicamente do revide legal de homens cujas esposas e filhas foram violentadas por outros homens, e que mais tarde foi classificado como crime por causa do dano que provoca. 
Portanto, assim como para o colono sua terra representa o bem mais precioso - pois expressa uma fonte inesgotável de recursos que garantem seu sustento e o de sua comunidade - para a mulher, sua sexualidade, seu desejo, são dádivas de inestimável valor - pois lhe permitem exercer seu papel insubstituível de gerar vida. Quando estes lhe são usurpados de maneira cruel e arbitrária, podem gerar prejuízos incalculáveis. Mies e Shiva, em Ecofeminism (1993), revelam a necessidade do homem branco colonizador em destruir a "natureza selvagem" dos colonizados, incluindo aí o corpo feminino, a "terceira colônia".

Existe um consenso entre teóricos feministas modernos em afirmar que o corpo não é apenas um elemento físico; antes, tem importante valor na construção da identidade individual e social da mulher (BONNICI, 2007). Daí a importância na construção da narrativa, que nos permite entender o motivo de obstinação da narradora em defender, tão impetuosamente, seu corpo contra o abuso sexual. Assim numa metáfora da mulher como colônia, a narradora reage energicamente para não ter usurpada e colonizada "sua terra".

\section{CONSIDERAÇÕES FINAIS}

No decorrer da história, a mulher tem visto seu espaço na sociedade ser relegado a um segundo plano e sua condição de subjugação tem sido a tônica dos discursos feministas. A escritora inglesa Angela Carter - perspicaz conhecedora dos mecanismos de opressão capazes de submeterem a mulher à marginalização - dá vida à sua personagem "sem nome", uma jovem inglesa do século XVII que se levanta contra a subjetificação da mulher frente aos sistemas colonial e patriarcal, e, antes mesmo de contar sua história, afirma-se como independente ao declarar que não se nomeará, senão por sua própria vontade ou quando lhe parecer mais oportuno.

A protagonista usufrui do seu discurso como poderoso instrumento linguístico em sua busca pela subjetificação. O discurso desconstrutivista da protagonista, a identificação das mulheres e a objetificação do homem, na narrativa, são instrumentos eficazes na construção da identidade do excluído. 
Além de oferecer subsídios claros para a formação de uma consciência crítica no leitor, a autora, mesclando ficção e história, revela aspectos importantes dos regimes colonial e patriarcal, os quais exerciam formas análogas de dominação sobre seus subordinados.

Elucidar e denunciar as táticas de dominação usadas por tais sistemas é de vital importância para gerar nos indivíduos atitudes de rompimento com os ditames dessas ideologias, fazendo-os levantar-se em defesa deles mesmos e também daqueles que padecem com o mesmo tipo de opressão.

Ainda que o colonialismo e patriarcalismo tenham causado profunda desestruturação na vida das mulheres, e mesmo que suas consequências sejam observadas nas sociedades atuais, há que se enfatizar que as estratégias da escrita e da leitura constituem admiráveis formas de resistência cultural (BONNICI, 2000).

Desse modo, Carter consegue produzir no leitor insatisfação e repulsa diante das atrocidades cometidas pelos detentores do poder em prejuízo de seus subordinados, a mulher e o indivíduo colonizado. Comprova, ainda, o importante papel que a literatura exerce sobre a sociedade, sendo capaz de motivar transformações não apenas no modo de pensar, mas também sendo competente para impulsionar atitudes dignas, resultantes de uma mente transformada pelo conhecimento.

\section{REFERÊNCIAS:}

ANDO, M. Y.; BONNICI, T. Entre a dominação e o revide: a resposta do colonizado em Apenas um curumim de Werner Zotz. Revista Ciências Humanas, Ciências Sociais Aplicadas, Linguística, Letras e Artes, v.13, n.2, UEPG p. 19-32, 2005.

ANDRADE, M. M. de. Introdução à Metodologia do Trabalho Científico. São Paulo: Atlas, 1995.

ASHCROFT, R.; GRIFFITHS, G.; TIFFIN, H. Key concepts in post-colonial studies. London: Routledge, 1998.

AZEVEDO, M. A. Mulheres espancadas: a violência denunciada. São Paulo: Cortez, 1995.

BONNICI, T. Conceitos-chave da teoria pós-colonial. Maringá, PR: Eduem, 2005.

O pós-colonialismo e a literatura: estratégias de leitura. Maringá: Eduem, 2000.

Short stories: an anthology for undergraduates: Maringá: Eduem, 2004. 
. Teoria e crítica literária feminista: conceitos e tendências. Maringá: Eduem, 2007.

BONNICI, T.; ZOLIN, L. Teoria literária: Abordagens Históricas e Tendências Contemporâneas. Maringá, PR: Eduem, 2.ed. 2005.

DuPLESSIS, R. B. Writing Beyond the Ending: Narrative Strategies of Twentieth Century Women Writers. Bloomington: Indiana UP. 1985.

LOOMBA, A. Colonialism/post-Colonialism. London: Routledge, 1998.

LUFT, C. P. Minidicionário Luft. 20.ed. São Paulo: Ática, 2001.

MARTINS, E. C. R. Cultura e poder. 2. Ed. São Paulo: Saraiva, 2007.

MIERS, M.; SHIVA, V. Ecofeminismo. v.71, Portugal: Ed. Piaget, 1997.

OLIVEIRA, A. A. G. O processo de subjetificação das personagens femininas em Disgrace (1999), de J. M Coetzee, Dissertação de Mestrado, UEM -Maringá : [s.n.], $2008.161 \mathrm{f}$.

PARADISO, S. R.; BARZOTTO, L. A.. A teoria, a literatura e a estética pós-colonial. Diálogos e Saberes, v. 3, p. 125-133, 2007.

. A. Transculturação em Our Lady of the masscre (1979), de Angela Carter. in: Acta Scientiarum. Language and Culture. v. 32, n. 1, p. 107-115, Maringá, PR: UEM, 2010.

STODDART, H. Angela Carter's night at the circus.[Routldge guide of Literature], London : Routledge, 2007.

TODOROV, T. A Conquista da América: a questão do outro. São Paulo: Martins Fontes, 1991.

VIANNA NETO, A. R. Multiculturalismo e pluriculturalismo. In: FIGUEIREDO, E. (Org.). Conceitos de literatura e cultura. Juiz de Fora: UFJF, 2005.

YOUNG, R. J. C. Postcolonialism: An Historical Introduction. Oxford: Blackwell, 2001.

RECEBIDO EM: 07 de maio de 2012

APROVADO EM: 12 de junho de 2012 